\title{
Does Reputation Contribute to Reducing Organizational Errors? A Learning Approach
}

\section{Mooweon Rhee}

\section{University of Hawaii}

ABSTRACT In this study I examine the effect of a firm's reputation for product quality on its effort in learning to reduce its product defect rate. Theoretical ideas on the motivation of learning associated with social aspiration levels and the self-serving bias combined with social categorization suggest that poor quality reputation firms are more likely than their counterparts with a good reputation to attend to potential product defects and consequently reduce their defect rate. However, a stream of research on the motivation of learning stemming from historical aspiration levels and slack search leads to a different argument: a reputation for good quality is more likely to provide firms with a motivation to avoid product defects. I build upon these two competing arguments and hypothesize that stronger motives for learning exist in situations where firms have either a weak or strong reputation for product quality. My study of product recalls in the US automotive industry highlights an inverted U-shaped relationship, indicating the liability of an intermediate reputation in reducing product defects.

\section{INTRODUGTION}

Recent surveys of corporate executives (e.g. Corporate Reputation Watch, 2004) demonstrate a strong recognition of the importance of reputation-oriented competition to a firm's success. In line with such practical imperatives, academic research has also demonstrated that among numerous competitive dimensions, corporate reputation is one of the most important competences for determining economic benefits and mitigating risks, differentiating one firm from others in an uncertain environment (Dowling, 2004; Fombrun, 1996; Horner, 2002). Since the publications of Akerlof's (1970) 'market for lemons' theory and Spence's (1974) 'market signalling' theory, many scholars in a variety of disciplines, including economics, marketing, management, and sociology, have sought to examine both the sources and consequences of corporate reputation, with a shared focus on information asymmetry or uncertainty around the relationship between

Address for reprints: Mooweon Rhee, Shidler College of Business, University of Hawaii, 2404 Maile Way, Honolulu, HI 96822, USA (mooweon@hawaii.edu). 
firms and their audience (see Rhee and Valdez (2009), Rindova et al. (2005) and Shenkar and Yuchtman-Yaar (1997) for comparisons of prior reputation studies across different studies).

While each discipline has a different definitional landscape of reputation (Fombrun and van Riel, 1997; Shenkar and Yuchtman-Yaar, 1997), an integrated perspective posits that possessing a reputation as a valuable organizational asset involves heightened 'awareness' ('being known') and/or favourable 'assessment' ('being good') from observers or stakeholders (Barnett et al., 2006; Carter, 2006; Rindova et al., 2005). This externally oriented definition of reputation, with few exceptions (e.g. Rhee and Haunschild, 2006), leads most empirical studies to investigate the positive effects of a good reputation on economic or social outcomes. Consistent with the emerging stream of research on identity construction from the standpoint of organizational members (Maguire and Phillips, 2008; Rodrigues and Child, 2008), however, a growing number of management studies are beginning to call for shifting attention from such 'pragmatic' perspective to internal, 'reflexive' view on reputation and status (Martins, 1998, 2005; Phillips and Zuckerman, 2001; Podolny and Castellucci, 1999; Pruzan, 2001; Stuart and Podolny, 1999). While existing identity-based approaches to reputation are primarily concerned with organizational identities imputed to a firm by its external audience and the effect of reputation on market performance (Barnett et al., 2006; Benjamin and Podolny, 1999; Dowling, 2004; Scott and Lane, 2000), the reflective perspective emphasizes how a reputation shaped by the imputed identity influences a focal firm's 'self-awareness' or 'self-assessment' in comparison with its competitors (Deephouse and Carter, 2005) and consequently, leads to certain behavioural outcomes such as change (Martins, 2005), identity management (Elsbach and Kramer, 1996), acts of conformity (Phillips and Zuckerman, 2001), or learning (Stuart and Podolny, 1999). For example, a poor reputation may facilitate a firm's search behaviour to overcome its reputational disadvantages but at the same time, the lower confidence in its capability associated with poor reputation can discourage its search attempts. However, the theoretical mechanisms that produce the behavioural consequence of reputation are still vaguely specified and remain empirically incipient.

In this study, I aim to advance theoretical considerations along with an empirical test, which can help elucidate the relationship between a firm's reputational position in the market and its behavioural outputs. I particularly examine the behavioural mechanisms by which firms attend to their potential errors and exert learning efforts to prevent such errors. Given the identity-based approach to reputation, I seek to explore such mechanisms by drawing on existing literature that presents identity-based views on organizational behaviour and more specifically, organizational attention and search.

The backdrop for my research is the behavioural theory of the firm. Extending Simon's (1947) work on the decision-making process, Cyert and March (1963), along with their colleagues and students, characterize firms as systems of structurally distributed attention, defined as encompassing the noticing, encoding, interpreting, and focusing of time and efforts by firms' decision makers. Relating the activation of attention to learning, the behavioural theory of the firm (Cyert and March, 1963; Greve, 2003; March, 1994; Winter, 1981) argues that search behaviour and learning occur when attention is focused on a problem area, whereas the intensity and speed of search behaviour and learning depend on the extent to which attention concentrates on or shifts 
away from that problem area. Given this, March $(1994,1996)$ and March et al. (2000) propose that the allocation of attention in organizations involves finding appropriate rules to follow and therefore is specified by institutional/cultural standards or norms linked to concepts of organizational identity. Following this identity-based view on organizational attention, Ocasio (1997) presents an imaginative model of situated attention in a firm to explain how the firm behaves and learns. An important principle in his model is that a decision-maker's focus depends upon the specific context that shares their identity. In particular, this perspective highlights the role of the decision-maker's structural position in regulating its attention and learning. Dutton and Dukerich's (1991) study particularly suggests that an organization's identity guides and activates its members' interpretation of non-traditional issues, such as organizational errors, and motivations for attention to these issues.

In this paper, I specifically argue that the perceptual position of a firm's quality, or quality reputation, plays a role in creating a unique set of interests, identities, and judgments, which then motivates or reduces the firm's attention to and search for solutions to potential errors, or product recalls in my empirical setting. While dealing with potential errors can involve more than motivation, such as firm capability (Rhee and Valdez, 2009), the errors examined in this study, i.e. product recalls in the automotive industry, appear to be closely coupled with the motivation of automakers operating in the US market (Haunschild and Rhee, 2004; see also my interviews with R\&D and quality control personnel of major automakers in the Methods section of this paper). Thus, this study limits its focus to the motivational aspect of reputation in its effects on the allocation of organizational attention and search behaviour.

Congruent with the definition of learning as problem-solving adaptive and corrective responses (Cyert and March, 1963; Lave and March, 1975), I use the term learning to reflect organizational processes that search for a way to improve organizational performance, or decrease unfavourable outcomes (product defects) in this study. While learning encompasses more than search behaviour, including experience accumulation, knowledge articulation, and knowledge codification (cf. Zollo and Winter, 2002), this study focuses on the consequence of reputation on attention allocation and search behaviour. Interestingly, existing literature on learning suggests two different views on the effect of quality reputation on learning effort to reduce product defects even though both views originate from the 'problemistic search' thesis (Cyert and March, 1963). On the one hand, scholars have found a negative relationship between a good reputational position and a motivation to search and learn (Podolny and Castellucci, 1999; Stuart and Podolny, 1999), suggesting a set of cognitive and behavioural mechanisms that support the positive effect of a reputation for low quality on attending to potential product defects. On the other hand, it is also possible to suggest that firms with a high quality reputation are motivated to address potential product defects and reduce their defect rate because sub-par performance prompts efforts to improve (Lant, 1992; Lant et al., 1992; Levinthal and March, 1981; Martins, 2005). These two mechanisms not only offer alternative views on the relationship between quality reputation and the motivation to search, but also operate simultaneously. Thus, the extent to which quality reputation affects learning to reduce product defects may be decided by the relative activation and effects of the two mechanisms. ${ }^{[1]}$ 
I examine the role of quality reputation, measured by examining historical quality ratings from consumers, in reducing product defects by investigating how the quality reputation of US automakers influenced their subsequent product recall rates over a 25 year period (1975-99). Building upon the focus on a firm's perception of its reputational position as a motivational driver of learning efforts, I am interested in examining whether a good or poor reputation motivates firms to learn to reduce subsequent product recalls. My hypotheses are, therefore, that a decrease in product recalls over time is connected to a firm's motivational learning process.

\section{THEORY AND HYPOTHESES}

In my theoretical discussion of the relationship between reputation and motivational learning, I focus on one reputational dimension, 'quality reputation' that is defined as the subjective evaluation of the perceived product quality of an organization (Rindova et al., 2005). Similar to the multifaceted nature of organizational identity (Cornelissen, 2006), there are various definitions of firm reputation depending on disciplines and empirical contexts as noted above (e.g. reputation in social responsibility, reputation in employee treatment; see Fombrun (1996) and Rindova et al. (2005) for a review). Brammer and Pavelin (2006) propose that the reputation effect of firm performance may vary both across industrial sectors and across various types of firm performance within sectors, and thus suggest the need to achieve a fit between the indicator and consequence of reputation across different study settings. The present study concentrates on the reputation for product quality because it investigates the effects of firm reputation when product quality is the issue, i.e. product recalls. In addition, product quality is shown to be one of the most important reputational dimensions in the automotive industry (Devaraj et al., 2001; Kotler, 2000; Rhee and Haunschild, 2006).

\section{The Positive Effects of a Reputation for Poor Quality on Learning}

A behavioural conception of firms (Cyert and March, 1963) argues that firms engage in search and change activities in response to performance feedback. The most important assumption under this behavioural theory of the firm is that organizational search and learning is 'stimulated by a problem and directed toward finding a solution to that problem' (p. 169). Psychologists and economists have also been interested in the effects of performance feedback on firms' adaptive behaviour (Crawford, 1995; Kahneman and Tversky, 1979). This performance feedback argument provides a rationale for why firms with a poor quality reputation show improved searching activity. According to one common theory, decision-makers classify a poor outcome relative to a social aspiration level, which is set by their reference group, as failure (Baum et al., 2005; De Clercq et al., 2008; Festinger, 1954; Greve, 1998, 2003), and such failure triggers increases in the frequency of adaptive searches (Cyert and March, 1963). Given that a firm's quality reputation may be regarded as its relative positional outcome (Deephouse and Carter, 2005; Podolny, 1993, 2001), firms with a poor quality reputation are likely to perceive their low positions as problematic, and thus be more motivated to scan for potential product defects and learn to reduce defects in their products over time. 
In a similar vein, one may argue that actors with a poor reputation are more likely than their counterparts with a good reputation to escape a phenomenon called the 'competency trap' (Levitt and March, 1988). A competency trap 'reflects the ways in which improving capabilities with one rule, technology, strategy, or practice interferes with changing that rule, technology, practice to another that is potentially superior' (March, 1994, p. 96). As a firm gains successful experience and attains proficiency at its current activities, it becomes more likely that those activities are reinforced and used, which leads to more success and so on. However, this positive feedback loop of experience, competence, and success can entrap a firm when favourable performance with an inferior technology leads the firm to accumulate more experience on this technology. It 'inoculate[es] against gaining competence at and using, another, possibly superior [technology]' (p. 251) or leads to a failure to experiment adequately (Arthur, 1989; Herriott et al., 1985). The competency trap argument implies that the likelihood of a firm's inattentiveness to new, possibly superior strategies, technologies, or routines is sensitive to the magnitude of the firm's success-induced confidence in the superiority of their current strategies, technology, or routines. The more confident a firm is of its existing routines, therefore, the more inattentive the firm is to alternative routines, because confidence will strengthen the mutual positive feedback between experience and competency.

Such feedback can also operate in the translation of reputation into a lack of search and learning. Compared to a poor reputation counterpart, a firm with a good quality reputation is likely to have stronger confidence in its existing practice. For example, a high level of accumulated quality ratings from consumers leads the producer to perceive its experience using the existing technical routine as a success. Such confidence will help the producer with a good reputation to repeat that technical routine and thus to become more proficient. However, the positive feedback loop between reputation and competency can backfire because the increased experience and competence induced by confidence in the current technical routine removes the producer from other experiences and knowledge and makes the producer less willing to attend to a new technical routine. Since the degree to which a firm attends to alternative opportunities is a function of its involvement in them (Cohen and Levinthal, 1994), committing its efforts to old competencies inhibits its willingness to pay attention to new opportunities. Thus, firms with a good quality reputation may be less willing than poor reputation counterparts to doubt their current technical routines and be less concerned about the possibility of product defects. In contrast, firms with a poor quality reputation may be more willing to question the reliability of existing routines and thus be more likely to explore new and potentially superior technologies that may proffer a better solution to product defects. ${ }^{[2]}$

The competency trap argument may also be supported by social identity theories, particularly research on self-serving bias and social categorization. The self-serving bias refers to the decision-maker's tendency to link internal attributes to positive outcomes, and external attributes to negative outcomes (Bradley, 1978; Zuckerman, 1979). For example, firms tend to attribute superior quality outcomes to their excellent technology and routines but are likely to attribute product defects to unfavourable environmental conditions or bad luck. This self-serving bias may lead firms to accentuate the use of their current routines and discourage their attention to alternatives that may help prevent product defects. However, social identity theories (Turner, 1987) suggest that such 
self-serving bias will be more prominent for good quality reputation actors than for their counterparts. According to Turner's (1987) research on self-categorization, actors selectively highlight those social dimensions that contribute to a positive identity but discount the dimensions that threaten the identity. Because a potential product defect is more likely to threaten firms with a good quality reputation, they will attempt to disassociate the defect from their reputation and blame the defect on external contingencies that are not associated with their technological competence. By contrast, for firms that have a poor quality reputation, a product defect may be regarded as an event that affirms their poor reputation. Thus, there is less room for firms with a poor quality reputation to blame lasting bad fortune on external circumstances, so they will be more motivated to employ various corrective measures to guard against product defects. I thus propose that the self-serving bias will be less likely to discourage firms with a poor quality reputation from adaptive searches for various quality controls that help them reduce product defects.

The aforementioned theoretical elaborations on the positive effects of a reputation for poor quality on motivation to reduce product defects have garnered direct support from several empirical studies. For example, Perretti and Negro (2006) and Stuart and Podolny (1999) show that actors with a poor reputation are more likely to engage in a search process, so-called 'exploratory learning' (March, 1991), to compensate for their low status in the market or organizations. Consistent with the 'performance feedback model' and 'competency trap thesis' discussed above, poor reputation actors are more willing than good reputation actors to doubt current routines, which they believe increases their reputational performance. Elsbach and Kramer's (1996) study on members' responses to organizational identity threats allows a more direct prediction that good reputation firms are more likely to ignore potential product defects, as indicated by social identity theories. Their main finding is that in response to a threat to their organization's identity, organization members use 'selective categorization tactics' to reemphasize positive perceptions of their organization's identities by deflecting members' attention away from the threatened identity dimensions. Assuming that a potential product defect can be perceived as an identity threatening, yet inescapable, error to firms with a good quality reputation, they may be less likely to highlight and address product defects as a dimension of product quality, so that their members are more inattentive to potential product defects as a target of learning and corrective response. This inattentiveness will impede the firm's search for solutions to reduce product defects (Cyert and March, 1963; Greve, 2003), suggesting that there are negative effects of a good reputation on a firm's motivation to learn how to reduce product defects.

Therefore, I propose the following hypothesis. ${ }^{[3]}$

Hypothesis 1a: An increase in a firm's reputation for quality is associated with an increase in the rate of its product defects.

\section{The Positive Effects of a Reputation for Good Quality on Learning}

A firm's adaptive search is also invoked when the firm's current performance is below a historical aspiration level, which is set by its own performance history (Crawford, 1995; Cyert and March, 1963; Levinthal and March, 1981). A firm's historical aspiration level 
is based in part on past performance, and increases with performance upturns and decreases with performance downturns (Lant, 1992). For example, a firm's history of its product quality can serve as a benchmark against which the firm evaluates its current quality level. Firms that have a history of providing quality products, represented as their good quality reputation, tend to have higher historical aspiration levels than firms with poor quality reputation. This indicates that firms with a good quality reputation are more likely than firms with a poor quality reputation to perceive a given potential product defect as performance below their historical aspiration levels. Martins' (2005) thesis on 'perceived identity-reputation discrepancy' proffers a similar suggestion that since the potential occurrence of a highly reputed firm's product defects is contrary to its own perception of its market standing, the firm is more likely to prepare preventive measures against product defects than its poorly reputed counterparts. Thus, firms with a reputation for good quality will be more likely to engage in adaptive search, which draws attention to potential product defects, stimulates risk taking behaviour, and encourages exploration of new practices to limit the occurrence of product defects over time (Baum et al., 2005; Greve, 1998, 2003; Lant et al., 1992; March and Shapira, 1992).

The behavioural theory of the firm also suggests that a high historical aspiration level will provide high quality reputation firms with a greater incentive to preserve their reputational performance and search for various ways to avoid any incidents that may damage their quality reputation (Cyert and March, 1963; Greve, 2003; Lant, 1992). Repeated or prominent defects in a firm's products may damage its quality reputation in the long run (Rhee and Valdez, 2009) and result in the loss of 'institutional trust' (Maguire and Phillips, 2008; Zucker, 1986) from the market audience. For example, prior studies find that the disclosure of product defects results in immediate losses in stock market valuation (Barber and Darrough, 1996) and product sales (Hoffer et al., 1994; Reilly and Hoffer, 1983) although the long-term effects caused by product defects are unclear. In their study of product recalls in the US automotive industry, Rhee and Haunschild (2006) demonstrate that good reputation can be a liability by showing that highly reputed firms are penalized more as a result of their product recalls. Thus, firms with a good reputation may be more likely to be attuned to potential product defects and allocate attention and resources to preventive measures against those defects.

Furthermore, a well regarded firm's greater motivation to prevent product defects can be compounded by its 'slack search' associated with its reputational position in the market. The notion of slack search suggests that a high degree of organizational slack (e.g. excess resources) facilitates experiments with new routines, while organizations without such slack would face challenges in experimentations (Levinthal and March, 1981). Greve (2003) presents a polished model of the process by which an organization's slack search results from slack resources that are used for the improvement of existing routines or the exploration of new procedures. He suggests that slack search often depends on intangible resources, such as free time and status, which motivates workers to take a risk in devising alternative solutions to actual and potential problems. Experimenting with alternatives may particularly pay off in mature industries where repeated problems or errors in organizations tend to be overcome by having more opportunities to depart from routinized procedures (Reason, 1997). Therefore, slack search promoted by a firm's perception of its reputational positions may have a positive consequence for 
the occurrence of product defects, or reduction in product defects over time, by providing the firm with more of such opportunities. A few studies (e.g. Perretti and Negro, 2006; Phillips and Zuckerman, 2001) lend empirical support to this speculation. Their findings suggest that well regarded actors are secure in their identity in the market, so are likely to maintain greater 'social psychological' or 'behavioural' slack for exploring novel, potentially better, designs and measures against potential product defects.

Taken together, these ideas support the following hypothesis.

Hypothesis 1b: An increase in a firm's reputation for quality is associated with a decrease in the rate of its product defects.

Given the two competing theoretical arguments proposed above, Hypotheses la or $1 \mathrm{~b}$ would be supported in the cases either where only one theoretical argument applies or where the positive effects of a good reputation overwhelm the positive effects of a poor reputation (or vice versa). The two upper graphs in Figure 1 present examples of those two hypotheses. The left upper graph indicates that variance in the positive effects of a reputation for good quality (solid line) are minimal compared to the variance in the positive effects of a reputation for poor quality (dotted line) so that the combined learning effects of reputations for good and poor quality (i.e. sum of solid and dotted lines) are higher for low-end reputation scores (' $\mathrm{L}$ ' in the graph). This case will support Hypothesis la. The right upper graph represents the opposite instance in support of Hypothesis $1 \mathrm{~b}$.

\section{Gurvilinear Relationships between Reputation and Learning}

If the positive effects of reputations for good and poor quality on learning are considered comparable in magnitude, however, a firm's motivational learning in response to reputational feedbacks would take on more complex features, such as an inverted or upright U-shaped relationship between quality reputation and a reduction in the rate of product defects (depending on the functional forms of the two competing learning mechanism as described below). ${ }^{[4]}$

On the one hand, the relative magnitude of the positive and negative effects of reputations for good and poor quality on learning may result in the liability of intermediate reputation (i.e. a level of reputation placed around the middle area along the measure of quality reputation), so that high and low reputations firms are more likely to reduce product defects than firms with an intermediate reputation. For example, it may be the case that the positive effects of a reputation for good quality on learning (e.g. from a slack search) accelerate as reputation scores increase while the positive effects of a reputation for poor quality on learning (e.g. from a problemistic search) accelerate as reputation scores decrease. The bottom left graph of Figure 1 illustrates such an example. This graph shows that the positive learning effects of reputations for high and low quality I discussed earlier have convex relationships with quality reputation, implying that as the quality reputation increases, the positive learning effects of good reputation increase at an increasing rate as shown by the solid line and that as quality reputation decreases, the positive learning effects of a poor reputation increase at an increasing rate as shown by the dotted line. Thus, the combined learning effects of reputations for good 

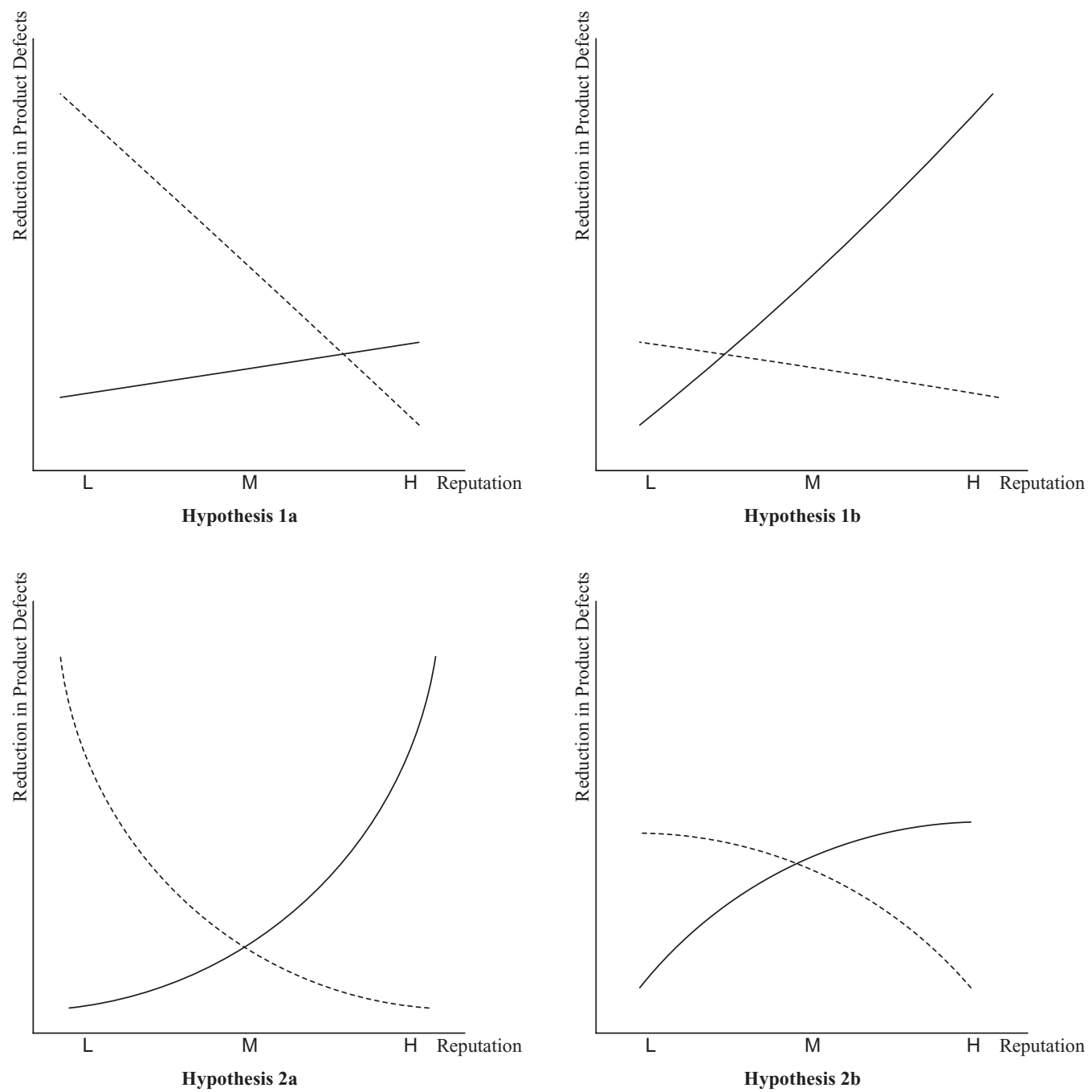

Figure 1. Functional forms for the relationship between quality reputation and reduction in product defects

and poor quality (i.e. sum of solid and dotted lines) are higher for high-end and low-end reputation scores ('H' and ' $L$ ' in the graph) than for middle area scores ('M'). So the lower level of combined learning effects in the middle area represents the liability of the intermediate reputation in reducing product defects. In short, a U-shaped relationship between quality reputation and the combined learning effects will result in an inverted $\mathrm{U}$-shaped relationship between quality reputation and the reduction in product defects.

Hypothesis 2a: A firm's quality reputation has an inverted U-shaped relationship with a decrease in the rate of product defects. 
On the other hand, the shifting balance of such reputation-based learning effects could operate in the opposite way, resulting in a positive effect for firms with an intermediate reputation. This is illustrated by the bottom right graph of Figure 1, where the positive effects of reputations for good and poor quality on learning earlier have convex relationships with quality reputation. This relationship suggests that as the quality reputation increases, the positive effects of a good reputation on learning increase at a decreasing rate (solid line) and that as the quality reputation decreases, the positive effects of poor reputation on learning increase at a decreasing rate (dotted line). Thus, the area (' $\mathrm{M}$ ' in the graph) that represents firms with an intermediate reputation has higher levels of the combined learning effects of good and poor quality reputations (i.e. sum of solid and dotted lines) than the high and low reputation areas (' $H$ ' and ' $L$ '). The higher levels of combined learning effects demonstrate that an intermediate reputation can be an asset in learning to avoid product defects. In conclusion, an inverted U-shaped relationship between quality reputation and combined learning effects will result in an upright $\mathrm{U}$-shaped relationship between quality reputation and the reduction in product defects.

Hypothesis 2b: A firm's quality reputation has a U-shaped relationship with a decrease in the rate of product defects.

\section{METHODS}

\section{Data and Sample}

As I noted earlier, my research setting is the automotive industry. The population in this study includes all automakers that sold passenger cars in the USA during at least one year from 1975 to 1999. During this period, 54 automakers sold passenger cars, and 72.2 per cent of these makers were non-US companies. Due to the limited access to information on the key covariates such as reputation, a few automakers are excluded from the study. The final sample includes 15 US automakers and 31 foreign automakers.

I focus on the automotive product recalls as an indicator of product defects. Since Congress passed the 'National Traffic and Motor Vehicle Safety Act' in 1966, automakers have been required to produce vehicles that meet federally determined safety standards. Automakers whose vehicles are deemed to be in non-compliance with standards are subject to motor vehicle or equipment recalls. I obtained data on all recalls for my sampled automakers from the Department of Transportation's National Highway and Traffic Safety Administration (NHTSA). The 46 automakers sampled in this study experienced a total of 1853 recall events over the period studied, for an average of 2.26 recalls per automaker per year. Table I shows the number of total recalls for each automaker in my sample over the study period.

Since my hypotheses test causal predictions about how a quality reputation impacts reduction in the rate of product recalls, which is a form of learning outcome, a more qualitative investigation was conducted to provide contextual evidence on the learning processes associated with automotive product recalls (Kim and Miner, 2007; Mason and Leek, 2008; Miner and Mezias, 1996; Schulz, 2002). Thus, I conducted written or oral interviews with three groups from four major automakers (Buick of GM, Ford, Hyundai, 
Table I. Number of total and severe recalls for each automaker, 1975-99

\begin{tabular}{|c|c|c|c|c|c|}
\hline Automaker & Total & Severe & Automaker & Total & Severe \\
\hline Acura & 8 & 3 & Lexus & 9 & 7 \\
\hline Alfa Romeo & 16 & 7 & Lincoln & 65 & 38 \\
\hline $\mathrm{AMC}$ & 22 & 12 & Mazda & 34 & 21 \\
\hline Audi & 32 & 21 & Mercedes-Benz & 32 & 18 \\
\hline BMW & 28 & 15 & Mercury & 130 & 69 \\
\hline Buick & 128 & 71 & MG & 5 & 2 \\
\hline Cadillac & 61 & 40 & Mitsubishi & 23 & 17 \\
\hline Chevrolet & 141 & 79 & Nissan & 27 & 15 \\
\hline Chrysler & 60 & 35 & Oldsmobile & 110 & 63 \\
\hline Daewoo & 3 & 2 & Opel & 3 & 2 \\
\hline Daihatsu & 1 & 1 & Peugeot & 10 & 4 \\
\hline Datsun & 3 & 2 & Plymouth & 80 & 42 \\
\hline Dodge & 101 & 54 & Pontiac & 133 & 65 \\
\hline Eagle & 27 & 14 & Porsche & 40 & 19 \\
\hline Fiat & 16 & 7 & Renault & 13 & 4 \\
\hline Ford & 145 & 77 & Saab & 45 & 18 \\
\hline Honda & 44 & 18 & Saturn & 16 & 9 \\
\hline Hyundai & 20 & 11 & Subaru & 34 & 15 \\
\hline Infiniti & 6 & 4 & Suzuki & 8 & 5 \\
\hline Isuzu & 7 & 2 & Toyota & 30 & 15 \\
\hline Jaguar & 28 & 15 & Triumph & 8 & 6 \\
\hline Kia & 5 & 3 & Volkswagen & 57 & 33 \\
\hline Lancia & 3 & 2 & Volvo & 36 & 18 \\
\hline
\end{tabular}

and Toyota) operating in the US market: R\&D, Quality Control, and Sales. I interviewed a senior level manager of each group (team or department) from all four automakers (i.e. 12 interviewees in total). I mainly focused my interview questions on the existence and mechanism of learning processes for reducing product recalls, which helped check the validity or feasibility of the assumptions embedded in my theoretical predictions and statistical models. I also had a series of follow-up interviews with some of the initial interviewees to consult about the interpretations of the results from my statistical analysis.

Interviews with R\&D personnel of all four automakers reveal that automakers certainly pay attention to recall events and attempt to decrease the recall rate, although the intensity of attention and learning efforts varied across automakers and contexts. An R\&D manager at Toyota explained how its R\&D team makes an effort to prevent recall events. Toyota has a task force for dealing with product recalls, where the causes of previous recalls are analysed, potential problems in their products are explored and fixed, and the improvement of product quality is pursued. A sales manager at Buick described how the sales team pushed its $\mathrm{R} \& \mathrm{D}$ team to attend to potential recall events. Because an automaker's recall event provides market competitors with 'a golden chance to show off and advertise their technological superiority' to customers, its sales team devotes substantial amount of attention to ways to escape this crisis (conversation with a Buick sales manager). 
In order to ascertain that paying attention to recall events is a matter of automaker motivation rather than of automaker capacity, I further interviewed R\&D and Quality Control personnel of the four major automakers to investigate the extent to which limited resources or capability constrains an automaker's ability to avoid product recalls. All interviewees agreed that automakers have little concern about such ability because almost all automakers have sufficient technical and financial capacity to prevent the recalls. As an R\&D manager in Toyota states, for example, 'No one can blame the lack of support from the top [of the firm] for product recalls. They [recalls] arise from carelessness or inappropriate resource allocation' (original in Japanese). A QC manager in Hyundai's manufacturing department lends support to this hypothesis in his e-mail to me: 'Product recalls are mainly associated with inadvertent attention allocation as evidenced by the fact that we [Hyundai] always successfully fixed the recalled products without much technical difficulty.' The interviewee also sent me a document demonstrating that all of Hyundai's recalls announced in the USA have been successfully resolved. But, one may suspect that some recall cases went to the court because fixing the recalls may have been beyond an automaker's technical capacity. As a R\&D manager at Ford said, however: 'it [taking a recall case into the court] is because we [Ford] do not admit our mistakes, not because we admit our lack of skills and capability.' Overall, my interviews confirm that the empirical context of this study allows me to focus on the motivational consequences of quality reputation to the exclusion of capacity consequence.

I also asked three interviewees (R\&D manager of Toyota, sales manager of Ford, and QC manager of Hyundai) about how motivational attention and learning to reduce product recalls are distributed among functional departments or value chain activities. While there is a variance in the distribution of job assignments on each function across the automakers, all interviewees agree that R\&D takes the presiding role in designing and manufacturing against product defects. As an R\&D manager of Toyota said, 'pressures toward zero defects come from the market competition, and our team [R\&D team] has the central responsibility for this mission' (original in Japanese). However, the R\&D team's learning effort to reduce product defects as a corrective response is always facilitated by the inputs from other activities including manufacturing, sales, and QC. For example, 'Our [QC team] effort to improve quality control system is critical for the reduction of product defects because for example, our report on quality tests, sometimes in comparison with competitors, can directly affect the challenges faced by R\&D team' (QC manager of Hyundai; original in Korean). Interestingly, a sales manager of Ford provided indirect, qualitative evidence that a quality reputation is associated with motivational attention and learning: 'our [perceived] quality position in the market stimulates us [sales team], and this stimulation then transfers to our R\&D team or our QC team.' This information suggests that the learning process of building a car involves not only knowledge transfer (Dyck et al., 2005) but also motivation transfer among value chain activities.

\section{Model}

For my hypotheses, I test whether the good and poor quality reputations of firms have an impact over time on product defect rates. Following many of the prior empirical studies 
on organizational learning, I focus on the improvement of an organization's performance as the primary learning outcome (see Argote, 1999 for a review), rather than the level of performance itself. Using performance improvement as a metric assumes that organizational learning leads to an increase in favourable outcomes or a decrease in unfavourable outcomes (Lave and March, 1975). For example, the more an automaker learns, the less likely that maker is to experience subsequent recalls. Several empirical learning studies suggest that changes in recall rates serve as a better proxy for learning outcomes than the absolute level of recall rate (cf. Argote, 1999; Greve, 1998; Haunschild and Rhee, 2004). That is, an automaker that has a lower recall rate than another automaker in a given year is not necessarily a better learner. The level of recall rate in a given year should be evaluated relative to the preceding year. Therefore, this study focuses on the reduction in the rate of product recalls to proxy for learning.

If $E_{i}$ denotes the number of automaker $i$ 's product recalls in a selected year, $t$, I model the determinants of change in recall rate using the following equation:

$$
E_{i}(t)=\alpha E_{i}(t-1)+\beta R_{i}(t-1)+\chi R_{i}^{2}(t-1)+\delta X_{i}(t-1)+\mu_{i}(t) .
$$

Here, $E_{i}$, refers to the number of recalls experienced by the automaker at $t-1$, or the lagged dependent variable, ${ }^{[5]}$ which is included to estimate change in recall rate. ${ }^{[6]} R_{i}$ refers to the quality reputation of automaker $i$ coded at $t-1,{ }^{[7]} X_{i}$ refers to control variables coded at $t-1$ (described below), and $\mu_{i}$ denotes an error term. Given Hypotheses $2 \mathrm{a}$ and 2b suggesting inverted U-shaped versus upright U-shaped relationships between quality reputation and the reduction in recall rates, I also add a squared term, $R_{i}^{2}$, to the equation. The positive and negative effect of this second derivative of quality reputation would imply a U-shaped and an inverted U-shaped relationship, respectively.

\section{Estimation Method}

I estimate the parameters of equation (1) in an unbalanced pooled cross-section time series data set with yearly time periods. Although such data can be modelled with fixed-effect estimators that analyse intra-firm variation over time, the larger inter-firm variations in quality reputation scores in my data make fixed-effects model less appealing. Thus, I use generalized estimating equations (GEE) or population-averaged (or marginal) estimators to analyse both inter- and intra-firm variation (Liang and Zeger, 1986). This estimation applies the quasi-likelihood approach to the analysis of longitudinal data, which specifies the relationship between the outcome mean and covariates and between the mean and variance, rather than the full distribution of population as is required for the cluster-specific maximum likelihood estimators such as fixed-effects model.

GEE estimators require a specification of the distribution for the dependent variable and a link function to connect the outcome to the covariates. Since the dependent variable in this analysis is a count measure as described below, I use the negative binomial estimator (Barron, 1992). I thus perform a GEE regression by choosing the negative binomial distribution and the log link. To account for autocorrelation among an automaker's observations, I also experiment with several working correlation matrices. Because autocorrelation turns out to be negligible, and effect estimates for covariates are 
very similar under alternative specifications of the working correlation structure, I choose the 'independent' version, as it produced the best model fit. In addition, as a check, I ran my analysis using fixed-effects model and found that the significance of the hypothesized effects did not change in the results.

\section{Measures}

Dependent variable. The dependent variable in equation $(1), L_{i}(t)$, is a count variable indicating the number of recalls from an automaker in a given year. However, my interviews with two senior managers in the auto industry suggest that an automaker's purpose regarding product recalls may not be to reduce to the recall rate itself, but to reduce the rate of severe recalls. The interviewees stated that limited resources and energy make it difficult for automakers to attempt to prevent all types of recalls, so automakers tend to pay attention only to severe recalls because severe recalls are more likely than non-severe recalls to be negative in the eyes of all constituents - manufacturers, consumers, and industry analysts. This is evidenced by Rhee and Haunschild's (2006) finding on the greater damage of severe recall events to market share. According to the rule of problemistic (problem-oriented) search (Cyert and March, 1963; Greve, 2003), such a focused attention to severe recalls suggests that automakers consider severe recalls more problematic than non-severe recalls and thus they are motivated to concentrate their search and learning for solutions on preventing severe recalls.

Following Haunschild and Rhee (2004), therefore, I construct a second learning performance dependent variable designed to capture the level of recall severity: the number of severe recalls for an automaker's current year-model vehicles. The NHTSA has established several criteria to judge each recall's level of severity. The NHTSA reports list the hazard level of the recall, with type 'a' representing significant hazard without the automaker's warning, type 'b' representing significant hazard with warning, type 'c' potential safety hazard, and type 'd' low risk of significant harm. As part of my analysis, I separate severe recalls (those involving significant hazard: 'a' or 'b') from non-severe recalls (type 'c' or ' $d$ '). The only difference between type 'a' recalls and type 'b' recalls is whether automakers provided consumers with warnings regarding the potential defects of the involved products prior to the first revelation of actual defects. The sample includes 1000 severe recall events (53.97 per cent of total recalls) over the period studied, for an average of 1.22 recalls per automaker per year. Table I reports the number of severe recalls for the automakers during the period 1975-99. ${ }^{[8]}$

Independent variable: quality reputation. Following Devaraj et al. (2001), Levin (2000) and Podolny and Hsu (2003), I use previous quality ratings provided by third parties to measure the reputation of product quality. This measure was also supported by a short questionnaire distributed to 19 persons with extensive auto industry experience. All respondents noted previous quality ratings as a key component of consumers' collective perception of product quality. Following their suggestion, I developed a measure of quality reputation using Consumer Reports: Buying Guide.

I used the 5-point scale 'trouble index' in Consumer Reports, which summarizes reliability for each trouble spot, as reported by respondents in the Consumers Union 
Annual Questionnaire. I calculated the mean of the 'overall problem rate' scores of each model for the most recent three years of ownership. I also used different years of ownership, but found little difference in the effect and significance (results are available from the author upon request). I then created an overall problem rate score for an automaker in a year by averaging the overall problem rate scores for all car models manufactured by the automaker in that year. Given that an automaker's quality reputation derives from the prior quality ratings of the maker, an average score over the five years prior to the selected year is used. Thus, my measure of an automaker $a$ 's quality reputation in the selected current year $T$ is formally defined as follows:

$$
C R_{a}=\sum_{T-5}^{T-1} \frac{1}{\mathcal{N}} \sum_{k=1}^{k=\mathcal{N}} \sum_{t-3}^{t-1} \frac{I_{k}}{3} .
$$

In this expression, $\mathcal{N}$ is the number of car models of automaker $a, t-1$ and $t-3$ denote the first and third year ownership of model $k$ cars of automaker $a$, respectively, and $I_{k}$ is the overall problem score of car model $k$ of automaker $a$.

Finally, following prior studies on reputation (e.g. Benjamin and Podolny, 1999; Phillips and Zuckerman, 2001), this measure is rescaled so that the automaker with the highest quality reputation in any given year has a score of ' 1 ' and the automaker with the lowest quality reputation has a score of ' 0 .'

Control variables. I control for several other factors that may affect an automaker's learning performance. First, organizational size and scope are important factors that have been found to affect organizational learning (Greve, 1998; Haunschild and Rhee, 2004; Haunschild and Sullivan, 2002). For example, large and generalist automakers are more likely to be inert in their attention to product recalls. Organizational size is measured as an automaker's yearly market share. I did not use total production volume as the size measure because this study focuses on auto recalls announced only in the USA. National production volume is also not an adequate size measure since many foreign (non-US) automakers manufacture their cars in their home countries and export them to the USA. An automaker' scope is proxied using two components. Following Dobrev et al. (2001, 2002), I first used the spread of engine capacity (measured in litres) over all car models that an automaker produced in a given year: largest engine capacity minus smallest engine capacity. Generalist automakers tend to produce cars with a wide range of engine sizes. Specialists produce cars with a small range (typically large) of engine sizes. I also measured the number of car models an automaker produced in a given year as an indicator of organizational scope. I then combined the two components into a single index of an automaker's scope using principal components analysis. A factor analysis confirms that those two scores are loaded on a single factor accounting for 78.7 per cent of the two scores' combined variance.

Second, I expect learning performance to vary with an automaker's experience, proxied by its production age in the learning performance analyses (Sorensen and Stuart, 2000). An automaker's age is measured as the differences between the current year and the time the automaker began car production. As shown in Table II, there is a large variance in production age across automakers. 
Reputation and Errors

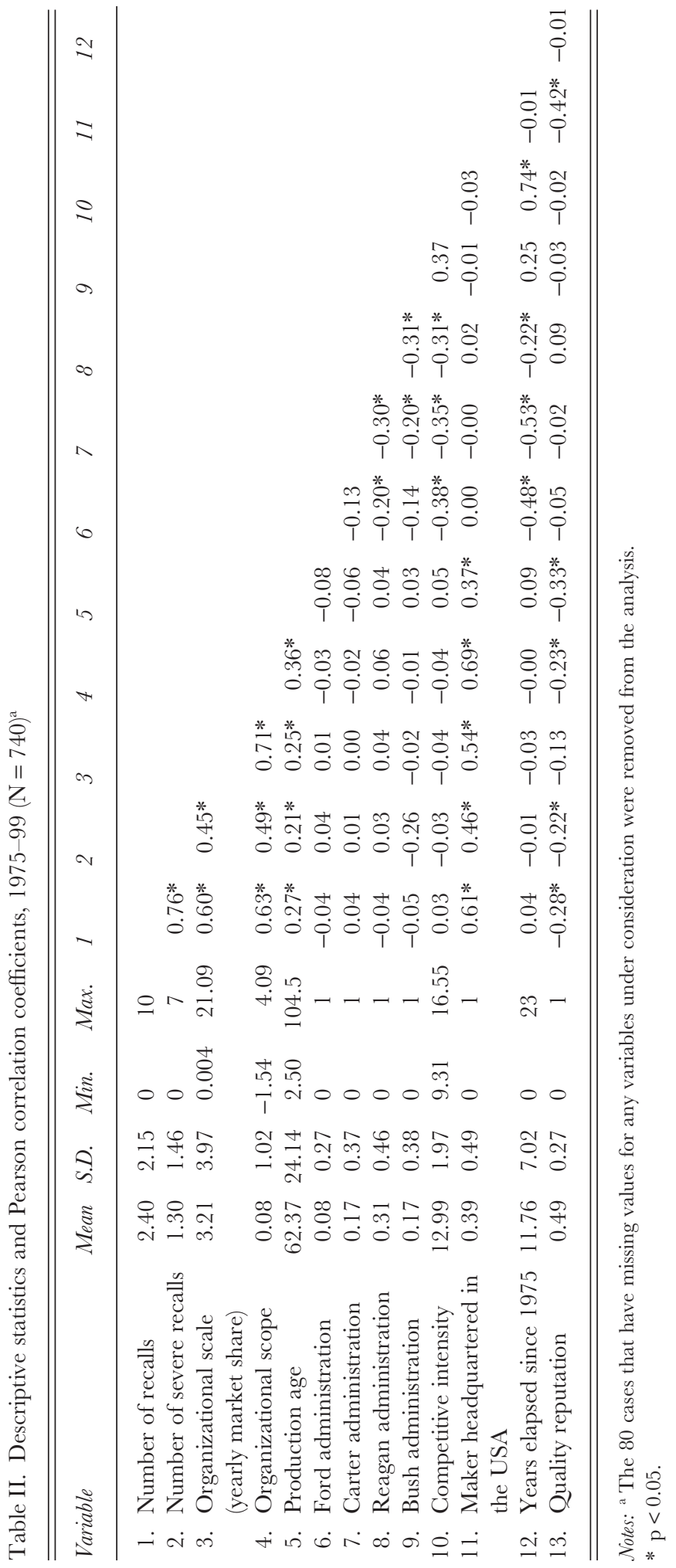


Finally, I also control for a combination of macroeconomic and social environments that my sampled firms face. First, I create a series of dummy variables (Ford, Carter, Reagan, and Bush) designed to capture the effects of a presidential administration, with Clinton as the excluded category. Governmental policy and regulations on the automobile industry may influence recall rates, as prior studies have shown that the amount of governmental control over automobile quality tends to increase during Democratic administrations and to decrease during Republican ones (Bromiley and Marcus, 1989; Haunschild and Rhee, 2004). Second, foreign automakers may face different governmental quality controls from domestic automakers, so I create a dummy variable for foreign automakers with the US automakers as the reference category. Third, I control for competitive intensity, which can also affect an organization's learning (Barnett and Hansen, 1996; Barnett and Sorenson, 2002; Ingram and Baum, 1997). Following the concept of market concentration, I measure competitive intensity using the inverse of the Herfindahl index of market share (Schilling and Steensma, 2001):

$$
C I_{t}=\frac{1}{\sum\left(m s_{i t}\right)^{2}}
$$

where $m s_{i t}$ represents automaker $i$ s market share in a given year with a possible maximum value of 1.00. Higher levels of this measure indicate higher competitive intensity. Finally, I include a variable measuring years elapsed from 1975 to capture any time trend effects associated with changes in the dependent variables. I also attempted to estimate period effects including year dummies instead of presidential administration and elapsed years. I could not find any noticeable significant effects of particular years. Also, this model produces a poorer model fit.

\section{RESULTS}

Descriptive statistics and correlations for the study variables used in the analyses of my hypotheses are shown in Table II. ${ }^{9]}$ The 80 cases (automaker-year spells) that have missing values for any variables under consideration were removed from the analysis. Table II shows that there are some fairly high correlations. Organizational scale and scope are correlated, which is not surprising given their strategic interactions. US automakers tend to be larger and have greater scope than foreign automakers. There is a high correlation between competitive intensity and years elapsed since 1975, indicating a growing trend in inter-firm competition. To investigate whether these correlations changed results of the models when correlated variables are used together, I ran separate regressions for each variable. Multicollinearity affected neither my hypothesized effects nor model fit.

A noticeable finding from the correlation matrix is a relatively low correlation (corr. $=-0.28$ ) between quality reputation and product recalls. This may support the theoretical assumptions of the study that having a high quality reputation does not necessarily indicate a lower recall rate and reversely, recall events do exert an immediate, negative consequence on quality reputation. My further investigation into the 
data was also consistent with a loose coupling between quality reputation and product recall rates. As of 1999, for example, Lexus recorded the highest quality reputation score and Hyundai recorded the lowest score, but the number of recalls announced by the two automakers was the same. These findings also appear to support the aforementioned qualitative evidence on the assumption that reducing product recalls is a problem of automaker motivation, rather than of automaker capacity. In addition, this loose coupling of quality reputation and product recall rates may also suggest some feature of the automobile market. Given that auto recalls are so widespread, consumers may not be able to discriminate and sanction automakers based on their recall rates. For example, Rhee and Haunschild (2006) find that only severe recalls damage an automaker's sales but non-severe recalls produce no harmful effect. This finding also suggests that an automaker's motivation to take corrective action and decrease product recalls varies depending on the severity of product recalls, which is consistent with the distinction of severe recalls from non-severe recalls as the dependent variable in my statistical model.

Table III displays the results from the negative binomial models of the recall rate (equation (1)), using GEE to test my hypotheses. The left column of each model estimates the subsequent rate of all types of recall events while the right column estimates the subsequent rate of only severe recall events. The two estimates show differences in the effects of some control variables, yet they produce comparable results for the hypothesized effects. Model 1 is the basic model and includes only control variables. The number of recalls in the prior year is positively related to the number of recalls in the current year, indicating an increasing recall rate during the consecutive years, which occurs probably due to contagious properties of error detection (see Haunschild and Rhee, 2004). However, this relationship is not observed for the number of severe recalls, which may support the idea that automakers are more motivated to reduce severe recalls than non-severe recalls. Organizational scope is a significant predictor of the subsequent recall rate and automakers headquartered in the USA show a higher subsequent recall rate than foreign automakers. There was a significant reduction in the rate of severe recall events during the Bush administration. Organizational scale is not significantly related to subsequent recall rates, which might be due to its high correlation with size.

In Model 2, I add the effect of an automaker's quality reputation. The coefficients for both dependent variables are non-significant. Thus, neither Hypothesis la nor Hypothesis $1 \mathrm{~b}$ is supported in this analysis. In Model 3, I include the quality reputation squared terms to test Hypotheses 2a and 2b. The two sub-models in Model 3 show that the first-order effects are positive and significant whereas the second-order effects are negative and significant for both dependent variables. Statistically significant improvements in Wald chi-square statistics from Model 2 to Model 3 show that adding the second-order effects substantially improves the fit of the model.

The qualitative implication of the results is illustrated in Figure 2, which plots the predicted multiplier of the subsequent recall rate for all types of recall events and severe recall events, based on the coefficients of quality reputation and its squared term in Model 3. In support of Hypothesis 2a, but not Hypothesis 2b, this figure shows an inverted U-shaped relationship between recall rates and quality reputation, providing evidence that high and low levels of reputations for quality produce more learning to 
Table III. GEE estimates of subsequent (severe) recall rates, 1975-99 $(\mathbf{N}=740)^{\mathrm{a}}$

\begin{tabular}{|c|c|c|c|c|c|c|}
\hline \multirow[t]{2}{*}{ Variable } & \multicolumn{2}{|c|}{ Model 1} & \multicolumn{2}{|c|}{ Model 2} & \multicolumn{2}{|c|}{ Model 3} \\
\hline & All & Severe & All & Severe & All & Severe \\
\hline \multirow[t]{2}{*}{ Number of (severe) recalls lagged } & $0.089 * *$ & 0.063 & $0.088 * *$ & 0.060 & $0.079 * *$ & 0.059 \\
\hline & $(0.029)$ & $(0.041)$ & $(0.029)$ & $(0.041)$ & $(0.030)$ & $(0.041)$ \\
\hline \multirow[t]{2}{*}{ Organizational scale } & $0.029 \dagger$ & 0.025 & $0.029 \dagger$ & 0.025 & $0.037 *$ & $0.032 \dagger$ \\
\hline & $(0.016)$ & $(0.017)$ & $(0.016)$ & $(0.017)$ & $(0.016)$ & $(0.018)$ \\
\hline \multirow[t]{2}{*}{ Organizational scope } & $0.156 *$ & $0.219 * *$ & $0.156 *$ & $0.221 * *$ & $0.150 \dagger$ & $0.212^{*}$ \\
\hline & $(0.076)$ & $(0.085)$ & $(0.076)$ & $(0.086)$ & $(0.077)$ & $(0.086)$ \\
\hline \multirow[t]{2}{*}{ Production age } & -0.000 & 0.001 & -0.000 & 0.001 & -0.002 & -0.001 \\
\hline & $(0.002)$ & $(0.002)$ & $(0.002)$ & $(0.002)$ & $(0.002)$ & $(0.003)$ \\
\hline \multirow[t]{2}{*}{ Ford administration } & -0.297 & -0.712 & -0.294 & -0.717 & -0.286 & -0.703 \\
\hline & (0.595) & $(0.684)$ & $(0.595)$ & $(0.685)$ & $(0.596)$ & $(0.685)$ \\
\hline \multirow[t]{2}{*}{ Carter administration } & -0.064 & -0.747 & -0.061 & -0.750 & -0.021 & -0.713 \\
\hline & $(0.508)$ & $(0.589)$ & $(0.508)$ & $(0.589)$ & $(0.509)$ & $(0.590)$ \\
\hline \multirow[t]{2}{*}{ Reagan administration } & -0.235 & -0.591 & -0.229 & -0.583 & -0.184 & -0.538 \\
\hline & $(0.347)$ & $(0.405)$ & $(0.347)$ & $(0.405)$ & $(0.347)$ & $(0.406)$ \\
\hline \multirow[t]{2}{*}{ Bush administration } & -0.239 & $-1.472 * *$ & -0.238 & $-1.478 * *$ & -0.220 & $-1.471 * *$ \\
\hline & $(0.194)$ & $(0.259)$ & $(0.194)$ & $(0.259)$ & $(0.194)$ & $(0.259)$ \\
\hline \multirow[t]{2}{*}{ Competitive intensity } & -0.002 & 0.002 & -0.003 & 0.003 & -0.004 & 0.001 \\
\hline & $(0.016)$ & $(0.018)$ & $(0.016)$ & $(0.018)$ & $(0.016)$ & $(0.018)$ \\
\hline \multirow[t]{2}{*}{ Makers headquartered in the USA } & $0.478 * *$ & $0.529 * *$ & $0.466 * *$ & $0.489 * *$ & $0.413^{* *}$ & $0.436^{* * *}$ \\
\hline & $(0.134)$ & $(0.150)$ & $(0.141)$ & $(0.156)$ & $(0.144)$ & $(0.162)$ \\
\hline \multirow[t]{2}{*}{ Years elapsed since 1975} & 0.003 & -0.026 & 0.003 & -0.026 & 0.005 & -0.024 \\
\hline & $(0.027)$ & $(0.030)$ & $(0.027)$ & $(0.030)$ & $(0.027)$ & $(0.031)$ \\
\hline \multirow[t]{2}{*}{ Quality reputation } & & & -0.068 & -0.001 & $1.264 \dagger$ & $2.093^{*}$ \\
\hline & & & $(0.201)$ & $(0.243)$ & $(0.686)$ & $(0.852)$ \\
\hline \multirow[t]{2}{*}{ Quality reputation squared } & & & & & $-1.406^{*}$ & $-2.205 * *$ \\
\hline & & & & & (0.688) & $(0.851)$ \\
\hline \multirow[t]{2}{*}{ Constant } & 0.542 & 0.211 & 0.582 & 0.330 & 0.565 & 0.325 \\
\hline & $(1.800)$ & $(2.162)$ & $(1.800)$ & $(2.173)$ & $(1.801)$ & $(2.172)$ \\
\hline Wald chi-square & $189.22^{* *}$ & $191.04 * *$ & $189.29 * *$ & $191.10^{* *}$ & $197.04 * *$ & $202.43^{* *}$ \\
\hline D.f. & 11 & 11 & 12 & 12 & 13 & 13 \\
\hline
\end{tabular}

Notes: ${ }^{a}$ The 80 cases that have missing values for any variables under consideration were removed from the analysis. $\dagger \mathrm{p}<0.10$; ${ }^{*} \mathrm{p}<0.05$; ** $\mathrm{p}<0.01$; two-tailed tests; Robust standard errors are in parentheses.

reduce product recalls than moderate levels of reputation. At its mean $(=0.49)$, quality reputation multiplies the subsequent rate of severe recall by a factor of 1.64 $(\exp [(2.093 \times 0.49)-(2.205 \times 0.24)])$. At one standard deviation $(=0.27)$ below its mean, reputation multiplies the subsequent rate of severe recall by a factor of 1.42 , and at one standard deviation above its mean, reputation multiplies the subsequent rate of severe recall by a factor of 1.37 .

Thus, the significant squared terms in Model 3 show that the positive learning effect is much larger than the negative learning effect at both high and low quality reputation levels. Both firms with a high and low reputation are in better positions than firms with an intermediate reputation to reduce recall rates. The results also show that the positive 


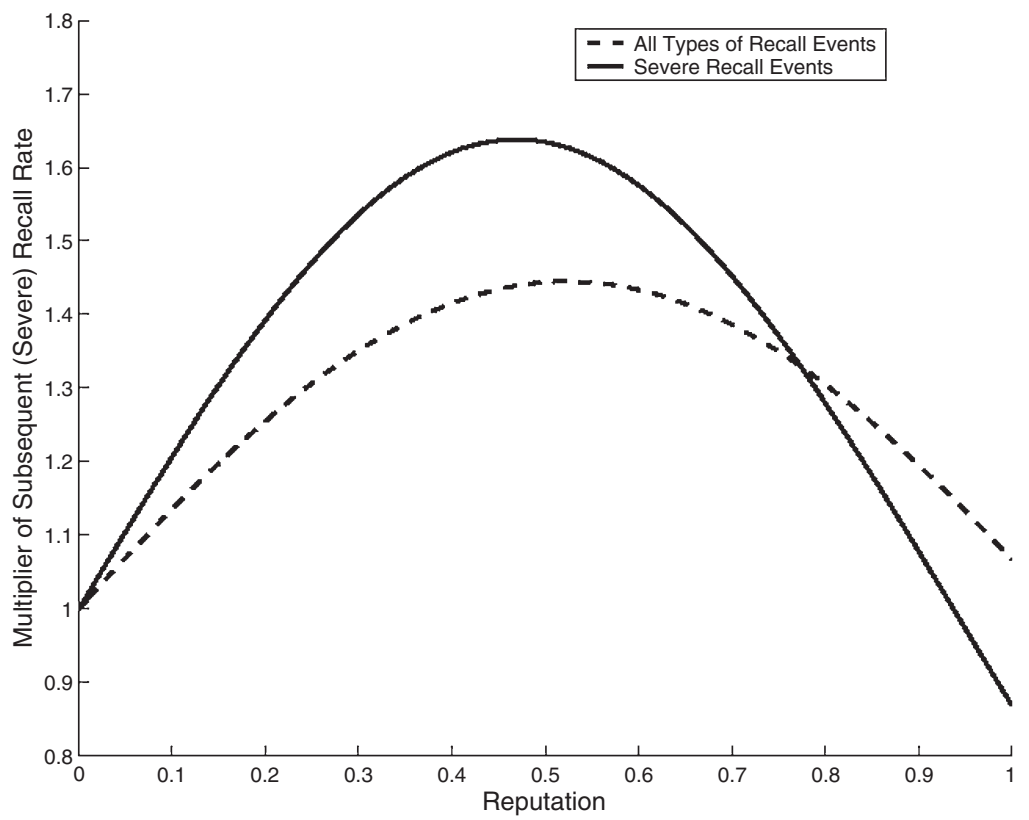

Figure 2. Predicted effect of quality reputation on subsequent (severe) recall rate

effects of high and low reputation on learning are larger when learning performance is measured as the reduction in severe recalls. This may suggest that reducing severe recalls is a more relevant learning target than reducing non-severe recalls.

Two industry experts I interviewed conveyed a practical interpretation of the inverted U-shaped relationship: Automakers with a high and low reputation allocate their attention to potential product recalls in the way that maximize positive learning effects while mitigating negative learning effects, but automakers with an intermediate reputation allocate their attention in an ineffective way, i.e. suffering from an unfavourable balance between positive learning effects and negative learning effects. This interpretation is also consistent with the instance illustrated in Figure 1 (Hypothesis 2a).

Theoretically, one possible mechanism underlying the observed non-monotonic relationship may be associated with an attention allocation rule (cf. March and Shapira, 1992; Ocasio, 1997), which suggests that firms pay differential attention to aspiration points (social versus historical) depending on their quality reputations. On one hand, firms with a poor quality reputation may pay more attention to social aspiration levels than to historical aspiration levels because adapting to a large gap beneath social aspiration levels is a more urgent issue. On the other hand, firms with a good quality reputation may be strongly concerned about the potential damages of product recalls, rather than resting on their higher reputational performance. Thus, the positive learning effects accruing to good quality reputation firms and poor reputation firms may be much higher than the negative learning effects. For firms with an intermediate reputation for quality, however, the gaps between social aspiration levels and reputational performance and between historical aspiration levels and potential product defects are not large enough to trigger their particular attention. 


\section{DISGUSSION AND GONGLUSIONS}

This study examined the relationships between a firm's quality reputation and its learning to reduce product defects. This study replicates and extends prior research on organizational reputation and learning in several respects.

First, the present study proffers a unique contribution to reputation studies by addressing a less explored research area. While most research on reputational effects is concerned with a firm's good reputation enhancing its market performance through signalling (Shapiro, 1983) and endorsement (Podolny, 1993) processes, including premium prices (Benjamin and Podolny, 1999; Rindova et al., 2005), superior financial performance (Preston and O'Bannon, 1997; Roberts and Dowling, 2002), and protection against market entrants (Ferguson et al., 2000; Milgrom and Roberts, 1982), this study joins a group of much fewer studies by examining the behavioural consequence of firm reputation. The effects of a firm's reputation on market performance are associated with how the market audience perceives the firm, whereas the effects of reputation on a firm's behaviour reflect how the firm responds to such perceptions. Although recent studies have sought to reveal various behavioural mechanisms underlying the effects of reputation on behavioural outcomes such as organizational search (Castellucci, 2001; Perretti and Negro, 2006; Stuart and Podolny, 1999) and change (Martins, 2005), there has been little discussion of the effects of reputation on a firm's motivation to reduce its potential errors. The contribution of this study is in showing that good and poor reputation firms are more motivated than firms with an intermediate reputation to reduce subsequent errors (product recalls in this study), resulting in the liability of intermediate reputation.

Second, this contribution also makes a significant contribution to learning research. While previous learning studies have examined a firm's learning behaviour to reduce its errors (Baum and Dahlin, 2007; Chuang and Baum, 2003; Haunschild and Rhee, 2004; Haunschild and Sullivan, 2002; Kim and Miner, 2007), few studies have explored how a firm's reputation influences such learning behaviour. This study may serve as a first response to calls for such research and finds a U-shaped relationship between reputation and learning effort to reduce product recalls. A behavioural theory of the firm conceptualizes organizational learning as the result of history-dependent, routine-based systems (Cyert and March, 1963). Yet not all learning systems are equal: a learning system interacts with reputation to affect error reduction. Theoretically, therefore, my findings help establish links between learning theories and theories of reputation. The contribution of this paper to learning theories lies in developing and showing the effects of a variable that is not yet well studied: a reputation for quality. The differential finding for firms with different quality reputation levels contributes to one tension in the learning literature: that of understanding the sources of variation in learning rates across different organizations (Argote, 1999).

Third, this study is a first attempt to investigate the context where a social aspiration level competes with a historical aspiration level in its influence on a firm's learning. In previous research (e.g. Baum et al., 2005; Greve, 1998, 2003), performance relative to social aspiration level and performance relative to historical aspiration level were found to have independent effects on a firm's search behaviour. In this study, however, I suggest 
that these two aspiration levels might intermingle in affecting a firm's learning to reduce product defects when its quality reputation is considered. I first proposed that firms with a poor quality reputation perceive that their reputational performance is below their social aspiration levels, which, along with less self-serving bias than their counterparts with a good reputation, help the firms escape the competency trap, attend to potential product defects, and learn to reduce the defect rate. I also proposed, however, that firms with a good quality reputation tend to have higher historical aspirations levels, which, along with their greater slack search, provide firms with the motivation to reduce potential product defects. My finding that an intermediate reputation for quality places firms in an adverse learning process suggests complex relationships between quality reputation and learning effects, as illustrated in Figure 1 (Hypothesis 2a).

My findings also have significant managerial implications, especially given that the disclosure of product defects, such as product recalls, has serious consequences for firms and their stakeholders (Barber and Darrough, 1996; Jarrell and Peltzman, 1985; Reilly and Hoffer, 1983). This study suggests that managers face critical, yet different challenges in learning to reduce product defects depending on the reputational position of their product quality in the market. Managers in firms with a good quality reputation should be careful of being locked in competency traps and self-serving biases. Managers in firms with a poor quality reputation should carefully consider the negative learning effects stemming from their low historical aspiration levels. In addition, given my finding of the liability associated with an intermediate reputation for quality, managers in firms with an intermediate reputation should understand that their firms are also vulnerable to the negative learning effects of both a reputation for good quality and a reputation for poor quality.

This may provide managers in firms with an intermediate reputation with a strategic signal warning them against a potential trap. As of 1999 in my sample, for example, Saab (quality reputation score $=0.492$ ) is placed close to the mean score, whereas Toyota (0.755) and Chevrolet (0.236) are respectively located near one standard deviation above and below the mean. According to the result of the estimation summarized in Figure 1, Toyota and Chevrolet are about 16 and 13 per cent more likely to attend to reducing subsequent recall rates than Saab. Given the previous research showing that the disclosure of product recalls is negatively associated with firm valuation or market performance because of a damaged image (Barber and Darrough, 1996; Reilly and Hoffer, 1983; Rhee and Haunschild, 2006), the result may suggest that Toyota reinforced its high reputation with improvements in reducing product recalls while such a reduction supplemented Chevrolet's quality reputation. In contrast, Saab did not benefit from such reinforcing or supplementing, and worse, its intermediate reputation was further tarnished by an increased recall rate. The practical implication, therefore, is that managers in Saab (and other automakers with an intermediate reputation) should remain cognizant of their reputation position to avoid potential image losses associated with a perceived lack of sustained performance and improvements in products recall rates.

Although this research makes several important contributions, my interpretation of the findings in this study should be considered in the context of a limitation. My explanation of the results requires the assumption that compared to firms with an intermediate quality reputation, firms with a good quality reputation and firms with a low quality reputation experience a greater sum of gaps between social aspiration level 
and reputational performance and between historical aspiration levels and potential product recalls. Without data on the aspiration levels of each firm, however, my interpretation may be quite speculative. More generally, access to information on aspiration levels may allow us to identify the directions in which the two alternative search mechanisms operate relative to each other. Hypotheses la and $1 \mathrm{~b}$ may imply competing directions, but the two search mechanisms may move in complementary ways. For example, it is possible to observe the case, in which a firm's reputational performance can be below its social aspiration level without being so low that all available resources needed for its search behaviour have been exhausted. While there may be several alternative learning mechanisms underlying the non-monotonic relationship in addition to my interpretations, however, this study could not test for those mechanisms due to the lack of information on each firm's social and historical aspiration levels. In future studies, more direct measures of social and historical aspiration levels would permit more convincing empirical demonstrations of my theoretical arguments, and I therefore regard the present study as first test rather than conclusive. However, I do view the results of this study as a first step in the direction of developing the literature on the reputational causes of organizational errors or product defects.

The restricted focus on the motivational consequence of quality reputation is another concern that future research also needs to address. Although such a restriction was allowed by my empirical setting, it is not difficult to expect more ample settings in which non-motivational processes will also apply. According to the reputation literature, the capacity consequence of reputation seems to be particularly prominent for a firm's attention to potential organizational errors. For example, a relational perspective on reputation (e.g. Podolny, 1993, 2001; Shane and Cable, 2002) suggests that firms with a reputation for good quality have a greater capacity to deal with potential product defects because of greater access to high-quality human resources, abundant financial capital, and excellent upstream suppliers or technology alliance partners, which may lead to a high level of R\&D and technological skills that would help reduce future product defects. In the settings where such internal and external resources are required to attend to potential organizational errors, therefore, it may be necessary to adapt a more integrative, generalizable model that addresses both motivational and capacity consequences of quality reputation. An intriguing research question from this model would be to examine whether motivation and capacity operate as complementary forces or competing forces in the relationship between quality reputation and product defects.

In addition, future reputation research could also benefit from a thorough examination of the long-term consequence of product defects on quality reputation. Although I did not find a direct link between quality reputation and product recalls in the current dataset, prior studies certainly suggest that product recalls may have a long-run, detrimental effect on quality reputation as information on a firm's recall events is accumulated and circulated through the mass media (cf. Rhee and Haunschild, 2006; Rindova et al., 2005). The possibility of a long-term consequence of product defects on quality reputation suggests two important implications for theories and empirical studies on reputation. First, while most previous studies measure a firm's quality reputation based on third party evaluations (see Fombrun, 1996; Podolny, 2005 for a review), finding such a consequence suggests that a firm's negative events, such as product recalls, could be a 
critical long-term proxy for quality reputation. Second, given the lack of studies on reputation/status evolution (Washington and Zajac, 2005), the negative long-term effects of product defects on reputation, combined with the results obtained in this study, represent a dual dynamic between quality reputation and product defects, and consequently may inform a mechanism underlying changes in reputation ordering.

Finally, I must caution against overgeneralization of the findings in this study. It might be that my arguments presented in the paper are more valid for contexts where: (1) a firm's relative reputational position serves as a strong motivator; (2) organizational errors are more of a motivational matter than a capacity matter (as noted above); and (3) product quality-based reputation is a core dimension of firm reputation. Relaxing some of these boundary conditions would require theoretical reformulations and empirical reexaminations. Regarding boundary condition (1), for example, while this study focused on the effects of reputational position in the market, for example, one may find from different settings that changes in reputation also affect a firm's motivation to reduce product defects. In a separate analysis I did not obtain a significant effect of reputation change on a reduction in product recalls, probably because organizations in the automotive industry pay more attention to their relative reputational status in the market than to changes in reputation, so the relative reputational status may have a greater behavioural consequence than its change. However, I do not rule out that there may be contexts where reputation change serves as a more prominent motivator for firms to engage in performance improvement or defects reduction efforts. For example, schools may tend to review and revise their strategic processes by reacting immediately to drops or spikes in their rankings than to the actual ranking. With respect to condition (3), as another example, given the multiple definitions and indicators of firm reputation across scholarly disciplines and empirical contexts (Rhee and Valdez, 2009; Rindova et al., 2005; Shenkar and Yuchtman-Yaar, 1997), the product quality-based reputation may be a less critical indicator of firm reputation than other reputational dimensions in other settings (Brammer and Pavelin, 2006), such as regional affiliation in the wine market (Benjamin and Podolny, 1999) or prominence in educational institutions (e.g. school reputation; Rindova et al., 2005).

\section{ACKNOWLEDGMENTS}

I would like to thank Pam Haunschild, Joep Cornelissen, Jim March, Joel Podolny, Ed Zajac, Bilian Sullivan, Ezra Zuckerman, and three anonymous $\mathcal{F} M S$ reviewers for their valuable comments. I am also grateful to Daegyu Yang for his research assistance.

\section{NOTES}

[1] Note that the two search mechanisms do not necessarily operate in an antagonistic way. They may even complement each other as addressed in the Conclusions and Discussion section.

[2] It is possible to speculate that firms with a high quality reputation are immune to the competency trap in their attempt to reduce product defects, because these firms may already have recorded a low rate of product defects, which is maintained as long as they preserve current procedures. I suspect, however, that quality reputation and product defects can be loosely connected, particularly when product defects are the result of insufficient motivation rather than a lack of capacity, so that firms with a good quality reputation can face the risk of relaxing their attention to product defects. This explanation is supported by my data showing a relatively low correlation between quality reputation and recall rates, as well as my interviews with automaker personnel (see the Methods section). 
[3] One may suspect that firms of poor reputation have less capacity to avoid products, so suggest a hypothesis of the opposing direction. As stated in the introduction of the paper, however, this hypothesis was derived after controlling for the capacity side of reputation, building upon the realistic assumption that the capacity issue does not come into play in my empirical setting. This assumption was supported by my interviews with automaker personnel as described in the Methods section. However, the need of future research to examine the capacity consequence of quality reputation for a more integrative framework is also proposed in the Discussion and Conclusions section.

[4] Note that the advantages of good and poor quality reputations do not directly lead to a U-shaped relationship between reputation and learning advantages (or inverted U-shaped relation ship between reputation and reduction in product defects). Unlike Phillips and Zuckerman's (2001) thesis on the middle status conformity derived from the condition that both high and low actors are more likely to deviate from the norm than middle status actors in terms of one particular dimension (i.e. sociopsychological security), my theoretical considerations are based on the assumption that the advantages of good reputation in a dimension indicate the disadvantages of poor reputation in the same dimension. Thus, it is not reasonable to hypothesize only an (inverted) U-shaped relationship in this study.

[5] Due to potential bias using the lagged dependent variable, I also used Arellano-Bond linear estimation in a separate analysis using the instrument matrix of lags of the dependent variables and the predetermined variables, and found very similar results on the significance of my key variables. I decided to report the results of the lagged dependent model because the Arellano-Bond model tends to accommodate the count dependent variable less efficiently.

[6] As alternative ways to estimate change in recall rates, I conducted separate analyses using two other change models: the partial adjustment model (Tuma and Hannan, 1984) and relative change models such as 'Gibrat's law' model (Carroll and Hannan, 2000, pp. 315-9). The results are fairly consistent with those presented in the text, but I did not use those models in the text due to their irrelevance for changes in a count variable that often violates certain assumptions underlying those models, such as linear time dependence, uncorrelated error terms, and homoskedasticity (Berry, 1993; Tuma and Hannan, 1984).

[7] The one-year time lag is consistent with the present study because it examines the effect of quality reputation on motivation-based attention to potential recalls (i.e. not learning from experience but attention-focused learning). I also obtained consistent results from two-year and three-year time lags, which is not surprising given the stable property of quality reputation over time.

[8] One may suspect that recall events tend to be concentrated at new car models. I closely examined each recall event and found that about 35 per cent of total recalls were associated with purely new models while the other 65 per cent involved purely old models or both new and old models. So I do not observe a significant difference in the distribution of recall events between new models and old models. I also sought to provide a complementary solution to this issue by controlling for the yearly number of all new models debuted by each automaker but, unfortunately, I could not find a complete source of this information.

[9] The fact that the number of recalls has a minimum of zero might result in a bias in the estimation of change in recall rate because the potential to reduce product recalls is systematically limited if there are no recalls in the previous year. I thus conducted two robustness checks in order to address this concern. First, I analysed the model excluding the cases (24 per cent of all cases) in which firms experienced no recall in the previous year. Second, I extended the lagged term up to three prior years so that the potential bias is reduced. Results from both analyses are consistent with those reported in the text.

\section{REFERENCES}

Akerlof, G. A. (1970). 'The market for "lemons": quality uncertainty and the market mechanism'. Quarterly Fournal of Economics, 84, 488-500.

Argote, L. (1999). Organizational Learning: Creating, Retaining and Transferring Knowledge. Boston, MA: Kluwer.

Arthur, W. B. (1989). 'Competing technologies, increasing returns and lock-in by historical events'. Economic fournal, 99, 106-31.

Barber, B. M. and Darrough, M. N. (1996). 'Product reliability and firm value: the experience of American and Japanese automakers, 1973-1992'. Fournal of Political Economy, 104, 1084-99.

Barnett, M. L., Jermier, J. M. and Lafferty, B. A. (2006). 'Corporate reputation: the definitional landscape'. Corporate Reputation Reviewe, 1, 26-38.

Barnett, W. P. and Hansen, M. T. (1996). 'The Red Queen in organizational evolution'. Strategic Management Fournal, 17, 139-58.

Barnett, W. P. and Sorenson, O. (2002). 'The Red Queen in organizational creation and development'. Industrial and Corporate Change, 11, 289-325. 
Barron, D. N. (1992). 'The analysis of count data: overdispersion and autocorrelation'. In Marsden, P. (Ed.), Sociological Methodology. Oxford: Blackwell, 179-220.

Baum, J. A. C. and Dahlin, K. (2007). 'Aspiration performance and railroads' rates of experiential learning from train wrecks and crashes'. Organization Science, 18, 368-85.

Baum, J. A. C., Rowley, T.J., Shipilov, A. V. and Chuang, Y.-T. (2005). 'Dancing with strangers: aspiration performance and the search for underwriting syndicate partners'. Administrative Science Quarterly, 50, 536-75.

Benjamin, B. A. and Podolny, J. M. (1999). 'Status, quality, and social order in California wine industry'. Administrative Science Quarterly, 44, 563-89.

Berry, W. D. (1993). Understanding Regression Assumptions. London: Sage.

Bradley, G. W. (1978). 'Self serving biases in the attribution process: a reexamination of the fact or fiction question'. Foumal of Personality and Social Psychology, 36, 56-71.

Brammer, S. J. and Pavelin, S. (2006). 'Corporate reputation and social performance: the importance of fit'. fournal of Management Studies, 43, 435-55.

Bromiley, P. and Marcus, A. A. (1989). 'The deterrent to dubious corporate behavior: probability and safety recalls'. Strategic Management fournal, 10, 233-50.

Carroll, G. R. and Hannan, M. T. (2000). The Demography of Corporations and Industries. Princeton, NJ: Princeton University Press.

Carter, S. M. (2006). 'The interaction of top management group, stakeholder, and situational factors on certain corporate reputation management activities'. Fournal of Management Studies, 43, 1145-76.

Castellucci, F. (2001). Status, Change, and Performance in Formula One Racing. Unpublished doctoral dissertation, Stanford University, Stanford, CA.

Chuang, Y.-T. and Baum, J. A. C. (2003). 'It's all in the name: failure-induced learning my multiunit chains'. Administrative Science Quarterly, 48, 33-60.

Cohen, W. M. and Levinthal, D. A. (1994). 'Fortune favors the prepared firm'. Management Science, 40, 227-51.

Cornelissen, J. P. (2006). 'Metaphor and the dynamics of knowledge in organization theory: a case study of the organizational identity metaphor'. Fournal of Management Studies, 43, 683-709.

Corporate Reputation Watch (2004). Global Survey of Senior Executive Opinions on Corporate Reputation Management. New York: Hill \& Knowlton.

Crawford, V. P. (1995). 'Adaptive dynamics in coordination games'. Econometrica, 63, 103-43.

Cyert, R. M. and March, J. G. (1963). A Behavioral Theory of the Firm. Englewood Cliff, NJ: Prentice Hall.

De Clercq, D., Sapienza, H. J. and Zaheer, A. (2008). 'Firm and group influences on venture capital firms' involvement in new ventures'. Fournal of Management Studies, 45, 1169-94.

Deephouse, D. L. and Carter, S. M. (2005). 'An examination of differences between organizational legitimacy and organizational reputation'. Fournal of Management Studies, 2, 329-60.

Devaraj, S., Matta, K. F. and Conlon, E. (2001). 'Product and service quality: the antecedents of customer loyalty in the automotive industry'. Production and Operations Management, 10, 424-39.

Dobrev, S. D., Kim, T.-Y. and Hannan, M. T. (2001). 'Dynamics of niche width and resource portioning'. American fournal of Sociology, 106, 1299-337.

Dobrev, S. D., Kim, T.-Y. and Carroll, G. R. (2002). 'The evolution of organizational niches: U.S. automobile manufacturers 1885-1981'. Administrative Science Quarterly, 47, 233-64.

Dowling, G. R. (2004). 'Journalists' evaluation of corporate reputations'. Corporate Reputation Review, 2 , $196-205$.

Dutton, J. E. and Dukerich, J. M. (1991). 'Keeping an eye on the mirror: image and identity in organizational adaptation'. Academy of Management fournal, 34, 517-54.

Dyck, B., Starke, F. A., Mischke, G. A. and Mauws, M. (2005). 'Learning to build a car: an empirical investigation of organizational learning'. Fournal of Management Studies, 42, 387-416.

Elsbach, K. D. and Kramer, R. M. (1996). 'Members' responses to organizational identity threats: encountering and countering the Business Week rankings'. Administrative Science Quarterly, 41, 442-76.

Ferguson, T. D., Deephouse, D. L. and Ferguson, W. L. (2000). 'Do strategic groups differ in reputation?'. Strategic Management Fournal, 21, 1195-214.

Festinger, L. (1954). 'A theory of social comparison processes'. Human Relations, 7, 117-40.

Fombrun, C. (1996). Reputation: Realizing Value from the Corporate Image. Boston, MA: Harvard Business School Press.

Fombrun, C. and van Riel, C. (1997). 'The reputational landscape'. Corporate Reputation Review, 1, 5-13.

Greve, H. R. (1998). 'Performance, aspirations, and risky organizational change'. Administrative Science Quarterly, 43, 58-86. 
Greve, H. R. (2003). 'A behavioral theory of R\&D expenditures and innovations: evidence from shipbuilding'. Academy of Management Fournal, 46, 685-702.

Haunschild, P. R. and Rhee, M. (2004). 'The role of volition in organizational learning: the case of automotive product recalls'. Management Science, 50, 1545-60.

Haunschild, P. R. and Sullivan, B. N. (2002). 'Learning from complexity: effects of airlines' heterogeneity of experience on learning from accidents and incidents'. Administrative Science Quarterly, 47, 609-43.

Herriott, S. R., Levinthal, D. A. and March, J. G. (1985). 'Learning from experience in organizations'. American Economic Review, 75, 298-302.

Hoffer, G. E., Pruitt, S. W. and Reilly, R. J. (1994). 'When recalls matter: factors affecting owner response to automotive recalls'. Foumal of Consumer Affairs, 28, 96-106.

Horner, J. (2002). 'Reputation and competition'. American Economic Review, 92, 644-63.

Ingram, P. and Baum, J. A. C. (1997). 'Opportunity and constraint: organizations' learning from the operating and competitive experience of industries'. Strategic Management fournal, 18, 75-98.

Jarrell, G. and Peltzman, S. (1985). 'The impact of product recalls on the wealth of sellers'. Fournal of Political Economy, 94, 512-36.

Kahneman, D. and Tversky, A. (1979). 'Prospect theory: an analysis of decision under risk'. Econometrica, 47, 263-91.

Kim, J.-Y. and Miner, A. S. (2007). 'Vicarious learning from the failure and near-failure of others: evidence from the U.S. commercial banking industry'. Academy of Management Fournal, 50, 687-714.

Kotler, P. (2000). Marketing Management, Millennium edition. Upper Saddle River, NJ: Prentice-Hall.

Lant, T. K. (1992). 'Aspiration level adaptation: an empirical exploration'. Management Science, 38, 623-44.

Lant, T. K., Milliken, F.J. and Batra, B. (1992). 'The role of managerial learning and interpretation in strategic persistence and reorientation: an empirical exploration'. Strategic Management fournal, 13, 585-608.

Lave, C. A. and March, J. G. (1975). An Introduction to Models in Social Sciences. New York: Harper and Row.

Levin, D. Z. (2000). 'Organizational learning and the transfer of knowledge: an investigation of quality improvement'. Organization Science, 11, 630-47.

Levinthal, D. A. and March, J. G. (1981). 'A model of adaptive organizational search'. Journal of Economic Behavior and Organization, 2, 307-33.

Levitt, B. and March, J. G. (1988). 'Organizational learning'. Annual Review of Sociology, 14, 319-40.

Liang, K.-Y. and Zeger, S. L. (1986). 'Longitudinal data analysis using generalized linear model'. Biometrika, 73, 13-22.

Maguire, S. and Phillips, N. (2008). 'Citibankers' at Citigroup: a study of the loss of institutional trust after a merger'. Journal of Management Studies, 45, 372-401.

March, J. G. (1991). 'Exploration and exploitation in organizational learning'. Organization Science, 2, $71-87$.

March, J. G. (1994). A Premier on Decision Making: How Decisions Happen. New York: Free Press.

March, J. G. (1996). 'Continuity and change in theories of organizational action'. Administrative Science Quarterly, 41, 278-87.

March, J. G. and Shapira, Z. (1992). 'Variable risk preferences and the focus of attention'. Psychological Review, 99, $172-83$.

March, J. G., Schulz, M. and Zhou, X. (2000). The Dynamics of Rules: Change in Written Organizational Codes. Stanford, CA: Stanford University Press.

Martins, L. (1998). 'The very visible hand of reputational rankings in US business schools'. Corporate Reputation Review, 1, 293-8.

Martins, L. L. (2005). 'A model of the effects of reputational rankings on organizational change'. Organization Science, 16, 701-20.

Mason, K. J. and Leek, S. (2008). 'Learning to build a supply network: an exploration of dynamic business models'. Fournal of Management Studies, 45, 774-99.

Milgrom, P. and Roberts, J. (1982). 'Predation, reputation, and entry deterrence'. Fournal of Economic Theory, 17, 280-312.

Miner, A. S. and Mezias, S. J. (1996). 'Ugly duckling no more: pasts and futures of organizational learning research'. Organization Science, 7, 88-99.

Ocasio, W. (1997). 'Toward an attention-based theory of the firm'. Strategic Management Fournal, 18, Summer, 187-206.

Perretti, F. and Negro, G. (2006). 'Filling empty seats: how status and organizational hierarchies affect exploration versus exploitation in team design'. Academy of Management Fournal, 49, 759-78.

Phillips, D. J. and Zuckerman, E. W. (2001). 'Middle-status conformity: theoretical restatement and empirical demonstration in two markets'. American Journal of Sociology, 107, 379-429.

Podolny, J. M. (1993). 'A status-based model of market competition'. American fournal of Sociology, 98, 829-72. 
Podolny,J. M. (2001). 'Networks as the pipes and prisms of the market'. American fournal of Sociology, 107, 33-60.

Podolny, J. M. (2005). Status Signals: A Sociological Study of Market Competition. Princeton, NJ: Princeton University Press.

Podolny, J. M. and Castellucci, F. (1999). 'Choosing ties from the inside of a prism: egocentric uncertainty and status in venture capital markets'. In Leenders, R. T. A. G. and Gabbay, S. M. (Eds), Corporate Social Capital and Liability, Norwell, MA: Kluwer, 431-45.

Podolny, J. M. and Hsu, G. (2003). 'The problem of Knightian uncertainty underlying exchange'. Research in the Sociology of Organizations, 20, 77-103.

Preston, L. E. and O'Bannon, D. P. (1997). 'The corporate social-financial performance relationship: a typology and analysis'. Business and Society, 36, 419-29.

Pruzan, P. (2001). 'Corporate reputation: image and identity'. Corporate Reputation Review, 1, 50-64.

Reason, J. (1997). Managing the Risks of Organizational Accidents. Aldershot: Ashgate.

Reilly, R. J. and Hoffer, G. E. (1983). 'Will retarding the information flow on automotive recalls affect consumer demand?'. Economic Inquiry, 21, 444-7.

Rhee, M. and Haunschild, P. R. (2006). 'The liability of good reputation: a study of product recalls in the U.S. automobile industry'. Organization Science, 17, 101-17.

Rhee, M. and Valdez, M. E. (2009). 'Contextual factors surrounding reputation damage with potential implications for reputation repair'. Academy of Management Review, 34, 146-68.

Rindova, V. P., Williamson, I. O., Petkova, A. P. and Sever, J. M. (2005). 'Being good or being known: an empirical examination of the dimensions, antecedents, and consequences of organizational reputation'. Academy of Management fournal, 48, 1033-49.

Roberts, P. W. and Dowling, G. R. (2002). 'Corporate reputation and sustained superior financial performance'. Strategic Management Fournal, 23, 1077-94.

Rodrigues, S. B. and Child, J. (2008). 'The development of corporate identity: a political perspective'. Fournal of Management Studies, 45, 885-911.

Schilling, M. A. and Steensma, H. K. (2001). 'The use of modular organizational forms: an industry-level analysis'. Academy of Management foumal, 44, 1149-68.

Schulz, M. (2002). 'Organizational learning'. In Baum, J. A. C. (Ed.), Companion to Organizations. Malden, MA: Blackwell, 415-41.

Scott, S. G. and Lane, V. R. (2000). 'A stakeholder approach to organizational identity'. Academy of Management Review, 25, 43-62.

Shane, S. and Cable, D. (2002). 'Network ties, reputation, and the financing of new ventures'. Management Science, 48, $364-81$.

Shapiro, C. (1983). 'Premiums for high quality products as returns to reputations'. Quarterly Fournal of Economics, 98, 659-80.

Shenkar, O. and Yuchtman-Yaar, E. (1997). 'Reputation, image, prestige and goodwill: an interdisciplinary approach to organizational standing'. Human Relations, 50, 1361-81.

Simon, H. A. (1947). Administrative Behavior: A Study of Decision-Making Processes in Administrative Organizations. Chicago, IL: Macmillan.

Sorensen, J. B. and Stuart, T. E. (2000). 'Aging, obsolescence, and organizational innovation'. Administrative Science Quarterly, 45, 81-112.

Spence, A. (1974). Market Signaling. Cambridge, MA: Harvard University Press.

Stuart, T. E. and Podolny, J. M. (1999). 'Positional consequences of strategic alliances in the semiconductor industry'. Research in the Sociology of Organizations, 16, 161-82.

Tuma, N. B. and Hannan, M. T. (1984). Social Dynamics: Models and Methods. Orlando, FL: Academic Press.

Turner, J. C. (1987). 'A self-categorization theory'. In Turner, J. C., Hogg, M. A., Oakes, P. J., Reicher, S. D. and Wetherell, M. S. (Eds), Rediscovering the Social Group: A Self Categorization Theory. New York: Basil Blackwell, 42-67.

Washington, M. and Zajac, E. J. (2005). 'Status evolution and competition: theory and evidence'. Academy of Management fournal, 48, 282-96.

Winter, S. G. (1981). 'Attention allocation and input proportions'. Fournal of Economic Behavior and Organizations, 2, 31-46.

Zollo, M. and Winter, S. G. (2002). 'Deliberate learning and the evolution of dynamic capabilities'. Organization Science, 13, 339-51.

Zucker, L. G. (1986). 'Production of trust: institutional sources of economic structure 1840-1920'. Research in Organizational Behavior, 8, 53-111.

Zuckerman, M. (1979). 'Attribution of success or failure revisited, or: the motivational bias is alive and well in attribution theory'. Fournal of Personality, 47, 245-87. 